\title{
SPATIOTEMPORAL PATTERNS AND ITS INSTABILITY OF LAND USE CHANGE IN FIVE CHINESE NODE CITIES OF THE BELT AND ROAD
}

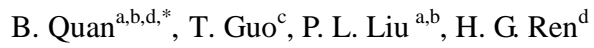 \\ ${ }^{\text {a }}$ College of City and Tourism, Hengyang Normal University, Hengyang 421002, People's Republic of China; \\ ${ }^{\mathrm{b}}$ Hengyang Base of the International Centre for natural and cultural heritage of the UNESCO, Hengyang Normal \\ University, Hengyang 421002, People's Republic of China - (quanbin308@aliyun.com, liu_peilin@126.com) \\ ${ }^{c}$ School of Computer Science and Engineering. Hunan University of Science and Technology, Taoyuan Road, \\ Xiangtan Hunan 411201, People's Republic of China - guotao0628@ outlook.com \\ ${ }^{\mathrm{d}}$ School of Resource, Environment and Safety Engineering. Hunan University of Science and Technology, \\ Taoyuan Road, Xiangtan Hunan 411201, People’s Republic of China - rhg365@ outlook.com
}

\section{Commission IV, WG IV/3}

KEY WORDS: Urban growth, Land use change, Flow matrix, Instability, Belt and Road

\begin{abstract}
:
It has long recognized that there exists three different terrain belt in China, i.e. east, central, and west can have very different impacts on the land use changes. It is therefore better understand how spatiotemporal patterns linked with processes and instability of land use change are evolving in China across different regions. This paper compares trends of the similarities and differences to understand the spatiotemporal characteristics and the linked processes i.e. states, incidents and instability of land use change of 5 Chinese cities which are located in the nodes of The Silk Road in China. The results show that on the whole, the more land transfer times and the more land categories involved changes happens in Quanzhou City, one of eastern China than those in central and western China. Basically, cities in central and western China such as Changsha, Kunming and Urumuqi City become instable while eastern city like Quanzhou City turns to be stable over time.
\end{abstract}




\section{INTRODUCTION}

Human activities make the range gradually transition from the natural ecosystem to the artificial ecosystem in the area around the city, which gradually become a region of intense human activity. The complex system coupled urban-nature system has a high degree of complexity, for local, regional and even the development of the global economy has a significant role. A complex system with the main elements of the humanities and the natural factors, the exchange of material flow, energy flow and information flow continuously with the external system, this is the result of the interaction between urban and natural complex system and other elements (Costanza, 1997; Liu, 2007; Chen et al., 2014). In 2008, more than 50\% of the world's population has been living in urban areas. by 2050 , the population will be living in the city of $66 \%$, while the rate of urbanization in China reached 90\% (Chneider et al. 2015). Study shows that the global city of the 67 regions of the world in 1970-2000, China is one of the most rapid cities in the process of urbanization (Seto et al., 2011). More than 30 years of reform and development, the population has increased by 500 million, urbanization rate increased from $19.4 \%$ to $49.2 \%$, increased by $29.8 \%$, as of 2012, more than $50 \%$ of China's population lives in urban areas (Chen et al., 2013; Kuang et al., 2014). China has become the most rapid development of urbanization in the world, which has been widely concerned by domestic and foreign scholars. Gu et al.,(2014) studied the change characteristics of urbanization in China from five stages (1980-2010) and the impact of urbanization on the process of urbanization. Mertes et al., (2015) using MODIS data to study the urban land use change of the thirteen countries in East. By contrast, China is the most rapid development of urbanization in East Asian countries. Chi et al., (2015) compared with China and the United States 1978-2010 urban internal space and time differences, analysis of the differences in urban land use structure of different countries, and to explore the reasons for the differences. Huang et al., (2015) studied the changes of urban land use in the three regions of the eastern, central and western regions.
Liu et al., (2015) further comparative analyzed the changes of urban land use in the East, northeast, central, western regions and Hong Kong, Macao and Taiwan regions in five regions of urban expansion.

With almost 30 years reformation and opening to abroad, China's urban economic system has gradually formed, the different scale, levels and functions of the city has a diverse range of links. Wu et al., (2015) use DMSP-OLS NIGHTTIME LIGHT (NTL) data to verify the levels of city. And the Chinese city is divided into seven urban nodes, 26 regional urban nodes, 107 nodes provincial city, which is basically the same division status as that of $\mathrm{Gu} \operatorname{did}(\mathrm{Gu}, 2008)$. Liu et al., (2012) regionalize China into 5 regions and analyzed the changes of land use during nearly two decades. In addition, Huang et al., (2015) applied the "first classification in grade, and second in class" ideas and $\mathrm{Q}$ cluster method to analyze regional difference and 23 Chinese urban structures were divided into 4 levels, i.e. nation, region, sub-region and locality.

These studies are mainly based on the regional level, and these findings provided much insight into land use change patterns, especially in large cities and large regions. However, a comprehensive examination of these findings with medium cities in the three different terrain of China is lacking up to date. It remains unclear that the differences of spatiotemporal patterns and processes such as states, incidents and instability of cities in different regions of China. To address these questions requires selecting and comparing several cities together using consistent method and data. Changsha, Kunming, Yinchuan and Urumqi and Quanzhou City are selected for this study due to the similarity in urban size and economy level. Moreover, they are respectively located in the eastern, central and western China, which is helpful to compare the differences in land change pattern and process (Figure. 1). In addition, they are major node cities on the Belt and Road and located in the Silk Road Economic Belt and the 21st-Century Maritime Silk Road. Thus they have important traffic location and the five cities form the "East - Central - West" transition. In this study, the primary research objective 
is to identify the similarities and differences in the processes i.e. states, incidents and instability of land spatiotemporal characteristics and the linked use change of 5 Chinese cities.

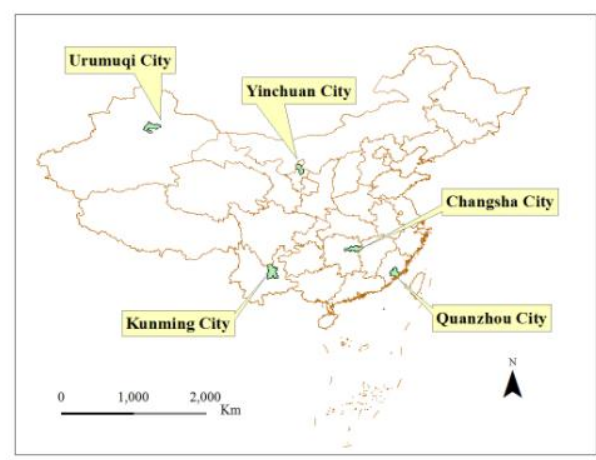

Figure 1. Location map of study area in the Belt and Road of China

\section{MATERIAL AND METHODS}

\subsection{Data sources}

Remote sensing images and their resolution, data sources, data format of Quanzhou, Changsha, Yinchuan, Urumuqi, Kunming are shown in Table 1 which is in accord with the 1: 100,000 land use classification. We consulted the land cover classification system from the China Environmental Sciences Remote Sensing Land Cover classification criteria. The land use classification system is: Built, Cropland, Orchard, Grassland, Water body, Forest, Unused land. In this study, IDRISI TerrSet and remote sensing are applied to process data.

\begin{tabular}{|c|c|c|c|}
\hline Cities & Data sources & Time points & Resolution \\
\hline Quanzhou & $\begin{array}{l}\text { I: } 100000 \text { vector data in } 1990 \text { is from China } \\
\text { Resources and Environmental Database; } \\
\text { 1995, 2000, 2005, } 2010 \text { Landsat TM, from the US } \\
\text { Geological Survey USGS; }\end{array}$ & $\begin{array}{l}1990 \text { is vector; } \\
\text { 1995, 2000, 2005, } 2010 \\
\text { are aster; }\end{array}$ & $30 \mathrm{~m}$ \\
\hline Changsha & $\begin{array}{l}\text { 1990, 1995, } 20001: 100000 \text { vector data from } \\
\text { China Resources and Environmental Database; } \\
\text { 2005, } 2010 \text { the TM / ETM from the US Geological } \\
\text { Survey USGS; }\end{array}$ & $\begin{array}{l}\text { 1990, 1995, } 2000 \text { are } \\
\text { vector; } \\
\text { 2005, } 2010 \text { are raster; }\end{array}$ & $30 \mathrm{~m}$ \\
\hline Kunming & $\begin{array}{l}\text { 1990, 2000, } 2008 \text { 1:100000 vector data are from } \\
\text { http://www.resdc.cn/Default.aspx. } \\
2014 \text { use Landsat } 8 \text { OL1,from geospatial data } \\
\text { cloud platform }\end{array}$ & $\begin{array}{l}\text { 1990, 2000, } 2008 \text { are } \\
\text { vector; } \\
2014 \text { is raster; }\end{array}$ & $30 \mathrm{~m}$ \\
\hline Yinchuan & $\begin{array}{l}\text { 1989, 1995, 2000, } 2007 \text { is the Landsat-5 TM; } 2014 \\
\text { is Landsat-8; They are from the Chinese Academy } \\
\text { of International Science Data Services Platform. }\end{array}$ & $\begin{array}{l}\text { 1989, 1995, 2000, } 2007, \\
2014 \text { are raster; }\end{array}$ & $30 \mathrm{~m}$ \\
\hline Urumuqi & $\begin{array}{l}\text { 1989, } 1999 \text { and } 2006 \text { are the TM / ETM + remote } \\
\text { sensing; } 2014 \text { is TIRS; They are from Earth } \\
\text { System Science Data Sharing Service Platform } \\
\text { and the US Geological Survey USGS. }\end{array}$ & $\begin{array}{l}\text { 1989, 1999, } 2006 \text { and } \\
2014 \text { are raster. }\end{array}$ & $30 \mathrm{~m}$ \\
\hline
\end{tabular}

Table 1 . The study area data sources 


\subsection{Methods}

\subsubsection{Incidents and States Algorithms}

In order to study the processing of urban land use changes, we applied a computer program in the language Visual Basic for Applications embedded in Microsoft Excel that interfaces with the GIS software TerrSet (Eastman 2014). A pixel's number of Incidents is the number of times the pixel experiences a change. Incidents can range from 0 , indicating complete persistence, to the number of time points minus 1 , indicating change across all time intervals. A pixel's number of States is the number of different categories that the pixel represents at all time points. States can range from 1, indicating complete persistence, to the smaller of the number of time points and the number of categories (Zhang, 2011; Runfola, Pontius, 2013; Zhang, Pontius, 2016). The two algorithms measure the multi-phase remote sensing image classification in spatial in different angles. The more detail is shown in Figure 2.

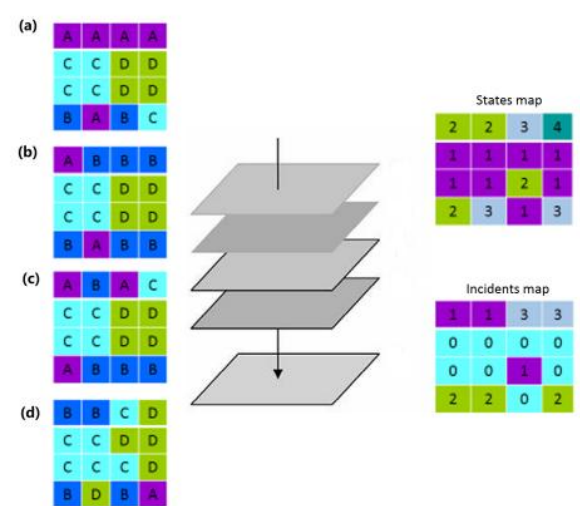

Figure 2. The number of land use the Incidents and the States algorithms

Incidents and States algorithms are extracted from the changes of pixels of the different period's remote sensing image classification results. A study area with a T-interval of remote sensing images, the results will produce $\mathrm{T}-1$ transition layers and $\mathrm{T}-1$ category layers, where the $\mathrm{t}$-th transition layer is generated by the time interval $\left[Y_{t}, Y_{t+l}\right]$.

As shown the left part of the Figure 2 (a)-(d) represents the different periods of urban land use remote sensing interpretation data. A, B, C and D represent the different periods remote sensing interpretation categories. The right is the results of the Incidents and States algorithm. Besides, the study divides the Incidents algorithm and States algorithm into pixel-level changes in the level and pattern of changes. Pixel-level changes include changes in the number of single and multiple category changes.

For example, there are 16 pixels in experimental data each time point. Each pixel is marked with numbers first from left to right, then from up to down among the 16 pixels distribution. It is divided into two arrangements: one is based on pixel level and another on pattern level. In the pixel level, Incidents algorithm includes one time and many times changes. Similarly, States algorithm includes single and multiple category change. Taking the 1 and 2 position as example, the single category and the multiple categories change ways in four different time points is: $\mathrm{A} \rightarrow \mathrm{A} \rightarrow \mathrm{A} \rightarrow \mathrm{B} \quad$ and $\quad \mathrm{A} \rightarrow \mathrm{B} \rightarrow \mathrm{B} \rightarrow \mathrm{B}$. multiple incidents and states include exchange transition and shift changes (Pontius and Santacruz, 2014). The 13 pixel position is exchange transition in which the way is: $\mathrm{B} \rightarrow \mathrm{B} \rightarrow \mathrm{A} \rightarrow \mathrm{B}$. While the $3,4,14$, 16 pixel position are shift changes, which is: $\mathrm{A} \rightarrow \mathrm{B} \rightarrow \mathrm{A} \rightarrow \mathrm{C}, \quad \mathrm{A} \rightarrow \mathrm{B} \rightarrow \mathrm{C} \rightarrow \mathrm{D}, \quad \mathrm{A} \rightarrow \mathrm{A} \rightarrow \mathrm{B} \rightarrow \mathrm{D}$ and $\mathrm{C} \rightarrow \mathrm{B} \rightarrow \mathrm{B} \rightarrow \mathrm{A}$.

The pattern level includes expansion and shrink mode. Expansion mode refers to the specific land 
category shows expansion along with the changes of surroundings. For example, the pixel symbolized with 5, 69 , and 10 is $\mathrm{C}$ in the period of the (d). On the 11 position, it coverts $\mathrm{D}$ into $\mathrm{C}$ in the time point of (d), which resulted in the quantity of $\mathrm{C}$ being increased. In contrast, the shrink mode refers to the specific land category shows decreased along with the changes of surroundings.

\subsubsection{Based on Flow Matrix of urban land use}

\section{change instability}

\section{(1) Flow Matrix Fundamentals}

For long time series of urban land use change study found that urban land use change occurred in the time dimension. Transition matrix of urban land use has become a major research analysis tool. It provides a simple theoretical basis for the comparison of the transfer and linking patterns to processes. (Duan, 2005; Qiao, 2013; Liu, 2010.). we use the Flow Matrix to study the Chinese typical urban land use change patterns in Quanzhou, Changsha, Kunming, Yinchuan and Urumuqi.

Flow Matrix refers to measuring transfer intensity index in the time interval $\left[Y_{t}, Y_{t+1}\right]$, which is a $(J+1) \times(J+1)$ matrix. It only shows the percentage of class i to class $\mathrm{j}$ in the interval $\left[Y_{t}, Y_{t+1}\right]$. In Table 2, the first $J+1$ column and $J+1$ row represent the net changes in urban land use. Flow Matrix that shows the change and the flow of information, is a method of measuring urban land use change and it is different from the transition matrix. The transfer matrix shows the size conversions. The Flow Matrix represents the total size of the amount transferred from class i to class $j$.

\begin{tabular}{|c|c|c|c|c|c|}
\hline & \multicolumn{4}{|c|}{ Time $t+1$} \\
\hline & & Category 1 & Category 2 & Category 3 & Gross Losses \\
\hline \multirow{4}{*}{ Time $\mathrm{t}$} & Category 1 & & $\frac{c_{12}}{\sum_{i=1}^{4} \sum_{j=1}^{4} c_{i j}}$ & $\frac{c_{13}}{\sum_{i=1}^{4} \sum_{j=1}^{4} c_{i j}}$ & $\frac{c_{12}+c_{13}+c_{14}}{\sum_{i=1}^{4} \sum_{j=1}^{4} c_{i j}}$ \\
\hline & Category 2 & $\frac{c_{21}}{\sum_{i=1}^{4} \sum_{j=1}^{4} c_{i j}}$ & & $\frac{c_{23}}{\sum_{i=1}^{4} \sum_{j=1}^{4} c_{i j}}$ & $\frac{c_{21}+c_{23}+c_{24}}{\sum_{i=1}^{4} \sum_{j=1}^{4} c_{i j}}$ \\
\hline & Category 3 & $\frac{c_{31}}{\sum_{i=1}^{4} \sum_{j=1}^{4} c_{i j}}$ & $\frac{c_{32}}{\sum_{i=1}^{4} \sum_{j=1}^{4} c_{i j}}$ & & $\frac{c_{31}+c_{32}+c_{34}}{\sum_{i=1}^{4} \sum_{j=1}^{4} c_{i j}}$ \\
\hline & Gross Gains & $\frac{c_{21}+c_{31}+c_{41}}{\sum_{i=1}^{4} \sum_{j=1}^{4} c_{i j}}$ & $\frac{c_{12}+c_{32}+c_{42}}{\sum_{i=1}^{4} \sum_{j=1}^{4} c_{i j}}$ & $\frac{c_{13}+c_{24}+c_{3}}{\sum_{i=1}^{4} \sum_{j=1}^{4} c_{i}}$ & $\sum_{i=1}^{4}\left[\left(\sum_{j=1}^{4} c_{i j}\right)-c_{i i}\right.$ \\
\hline
\end{tabular}

Table 2. The Flow Matrix form (Runfola, Pontius, 2013)

(2) Based on Flow Matrix to calculate urban land use change instability

Eq. 1 and Eq. 2 are the foundation of calculating urban land use instability. Eq.1 changes calculated observe intensity $\mathrm{S}$ in each time interval; the Eq.2 calculated uniform intensity $U$ of the entire study period. After calculating the observe intensity in each time interval, we compared with uniform intensity which is compares $\mathrm{S}$ to $\mathrm{U}$. if $S>U$, then the change is relatively fast for that time interval. If $S<U$, then the change is relatively slow for that time interval. (Aldwaik, Pontius, 2012; Pontius, Gao et al., 2013; Zara, João, Pontius, 2016; Enaruvbe, Pontius, 2015).
Eq.3 calculated land category change instability index $\mathrm{R}$ in differently intervals. Numerator is the maximum of the observe intensity in special time interval and uniform intensity in different time interval. And the denominator is uniform intensity multiplying by the whole time interval. The ratio of numerator and denominator is $R$, which is a calculated measure of urban land use change. If $R=0$, the change is absolute stability, that is $S=U$. The $R>0$, the change is instable.

$$
\mathrm{S}=\frac{\left\{\sum_{\mathrm{j}=1}^{\mathrm{J}}\left[\left(\sum_{i=1}^{J} \mathrm{~s}_{\mathrm{tij}}\right)-\mathrm{s}_{\mathrm{tij}}\right]\right\}}{\left(\mathrm{Y}_{\mathrm{t}+1}-Y_{t}\right)}
$$




$$
\begin{array}{r}
\mathrm{U}=\frac{\sum_{t=1}^{T-1}\left\{\sum_{j=1}^{J}\left[\left(\sum_{i=1}^{J} s_{t i j}\right)-s_{t i j}\right]\right\}}{\left(Y_{T}-Y_{1}\right)} \\
\mathrm{R}=\frac{\sum_{t=1}^{T-1}\left\{\operatorname{MAXIMUM}[0,(S-U)] \times\left(Y_{t+1}-Y_{t}\right)\right\}}{U \times\left(Y_{T}-Y_{1}\right)}
\end{array}
$$

The maximum value of $R$ can be manifeste $\mathrm{d}$ in the shortest time interval range. Within a $\mathrm{r}$ ange of urban land use change, only drastic cate gory changes in the shortest possible time interv als range, while in the other interval range categ

\section{RESUILS}

Figure 3. provide maps of each city in which legend colors indicate more frequent transitions over

ory changes slowly. Based on the Eq. 4 we cal culates the maximum of $\mathrm{R}$, i.e. $R_{\max }$.

$$
R_{\max }=1-\frac{Y_{d+1}-Y_{d}}{Y_{\mathrm{T}}-Y_{1}}
$$

When the shortest time interval is reduced, $R$ max gradually approaches 1 , when the length of $t$ he time interval is ignored, $R_{\max }$ minimum value close to 0 .

time. In these figures, zero in the legend indicates persistence across the time extent. The maximum value for any pixel in these maps is equal to the number of time intervals.

\begin{tabular}{|l|l|l|c|}
\hline Typical city & Main types land use & Year of land use & Data resolution \\
\hline Quanzhou & Built, Cropland, Orchard & $1990,1995,2000,2005,2010$ & 100 \\
Changsha & Cropland, Grassland, Forest & $1990,1995,2000,2005,2010$ & 100 \\
Kunming & Forest, Grassland, Built & $1990,2000,2008,2014$ & 100 \\
Yinchuan & Cropland, Built, Grassland & $1989,1995,2000,2007,2014$ & 30 \\
Urumuqi & Cropland, Grassland, Built, Unused land & $1990,1999,2006,2014$ & 100 \\
\hline
\end{tabular}

Tab. 3 The characteristics of typical city land use data

incidents Map of Quanzhou is shown in Figure 3(a). It indicated that the frequency mainly dominated by 1 time and 2 times, which are accounted for $31.5 \%$ and $41.4 \%$, respectively. These changes are mainly located in the ring of Quanzhou Bay Coastal and economic development Zone of Quanzhou. It is because that it is flat for central and southeast of Quanzhou, and so human activities often put a pressure on the land use. It is accounted for $18.5 \%$ that the Transition Frequency of times reaches three times. These changes occurs mainly in Dehua, Yongchun and Jinmen County. There is a cycle of fast-growing of forest cultivation, so the remote sensing images show a "Forest land - woodland orchard - artificial turf - orchard - woodland "change sequence (Zhang et al, 2012). 

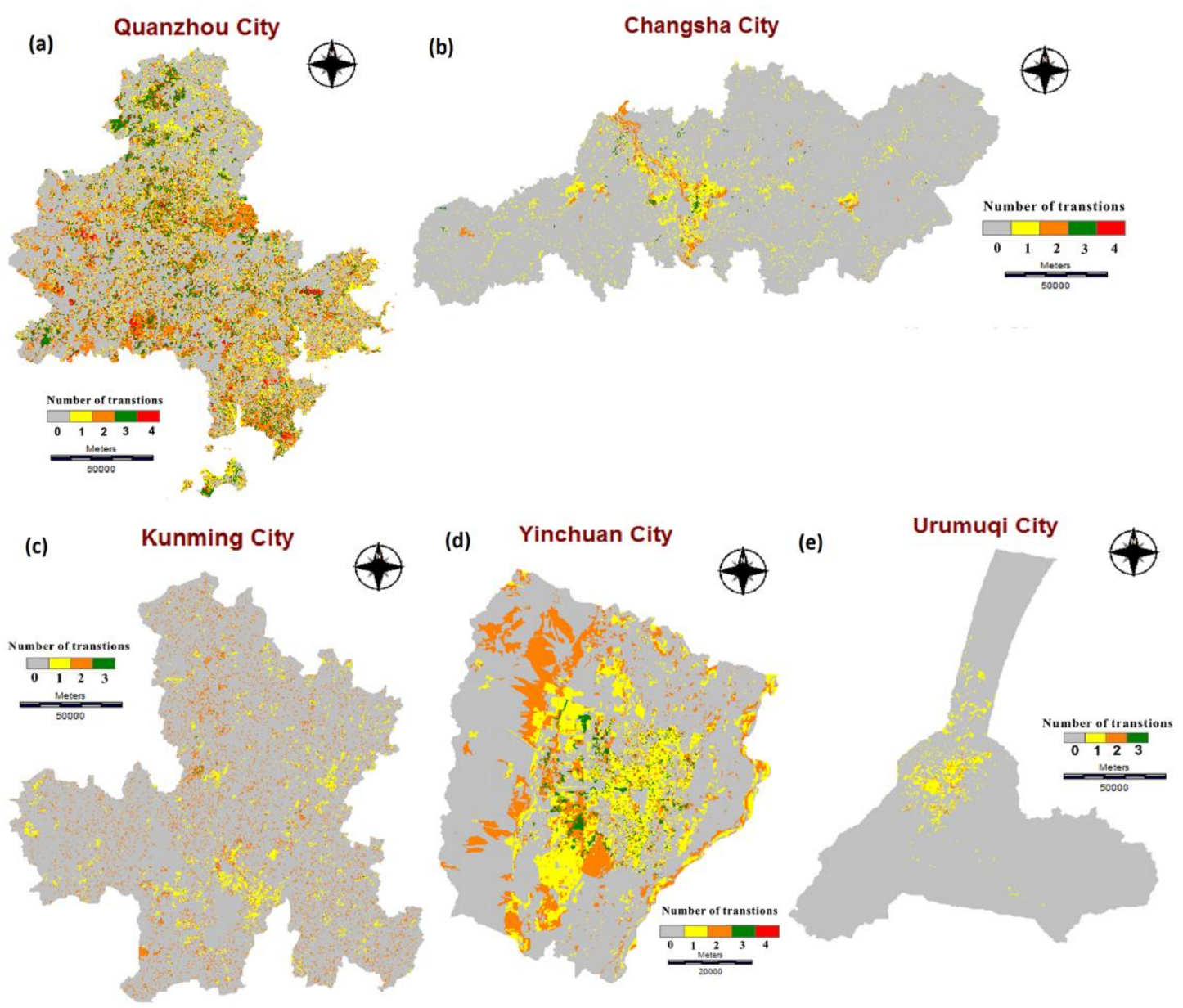

Figure 3. The Incidents map in the typical cities.

Figure 3(b) is a four interpretation of remote sensing data obtained the transition frequency of Urumuqi urban land use. The 1 time land category transition is mainly accounted for the $91 \%$. Generally, Cropland, Grassland and Bare were converted to the Built, which happens mainly in the Midong and Tianshan District. The 2 times only accounted for $8.6 \%$ whose land conversion is as follows: Grassland $\rightarrow$ Cropland $\rightarrow$ Built. Figure 3 (c)-(e) shows the times of transition for Kunming City. In Kunming, the 1 and 2 times of land transition are accounted for $34.7 \%$ and $64.8 \%$, respectively. In the northwest of Luquan Yi and Miao Autonomous County and Dongchuan District are mainly forest, Cropland and Grassland. Panlong, Wuhua Guandu District is mainly construction land. It appears around the Xishan, Jinning, Chenggong District are water in the form of the distribution network. The 1 time and 2 times transfer are mainly for Cropland, Forest and Grassland carrying changes between both or all three. In the Jinfeng District, Xingqing district and eastern Helan County there is distribution of Built and Crop land. In Xixia, Yongning County, and western Helan County are distribution of forest, grassland and unused land. Yinchuan City distributed waters in the east. The land that transfer 1 time and 2 times are mainly Cropland, Forest and grassland. For Yinchuan City, land that transfer 1 and 2 times are mainly distributed in the Jinfeng District, Xingqing district, northern Xixia district and central Helan Mountain. The occurrence of urban land use change is: Cropland $\rightarrow$ Built, Forest $\rightarrow$ Built and Unused land $\rightarrow$ Cropland, and so on. For Changsha, the land that transfers 1 and 2 times accounted for $75.6 \%$ and $20.2 \%$, which happens in Liuyang River and Changsha urban area.

Figure 4 shows the comparison of land transfer frequency of five typical cities. Kunming and Urumuqi both mainly occur to divert 1 time, 
accounting for $97.8 \%$ and $91 \%$, respectively. Land use change happened in the two areas mainly in a way of exchange. Quanzhou occurs one, two and three times with the way of swap changes, accounting for $31.2 \%$, $43.4 \%$ and $18.5 \%$, respectively. Changsha and Yinchuan were mainly in 1st and 2nd times change. In short, we can conclude that the 1 time transfer happened in five cities mainly is Cropland being

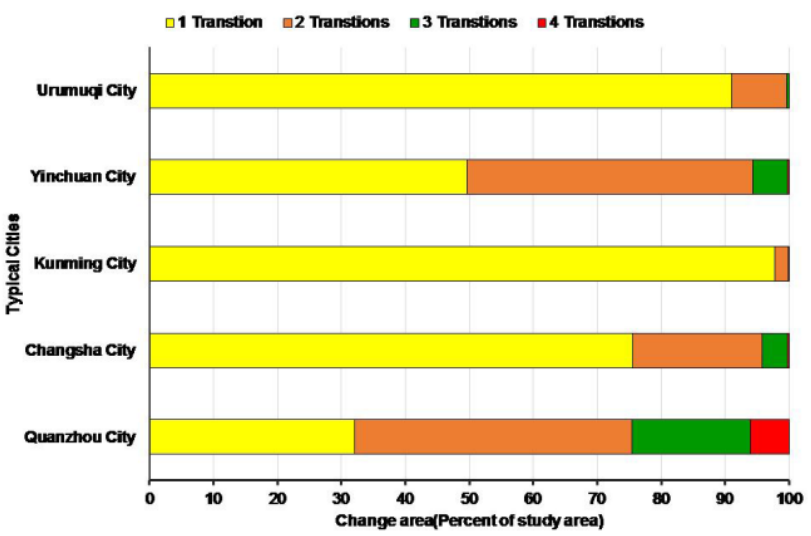

Figure 4. The land use change of Incidents

We calculate the observed changes $\mathrm{S}$ and uniform intensity based on Eq. 1 and Eq. 2 in Figure 5. We can see that except the Yinchuan City, the cities in central and western China such as Changsha, Kunming and Urumuqi City become instable while eastern city like Quanzhou City turns to stable over time. Obviously, from the instability perspective, the converted to Built. And on the whole, the more times of land transfer in the developed eastern coastal region of China, e.g., Quanzhou City is more than that of central and western region. The reason possibly is that the land change tend to drag on growth in developed eastern coastal region of China. In this case Quanzhou pays attention to the forest cultivation and protection.

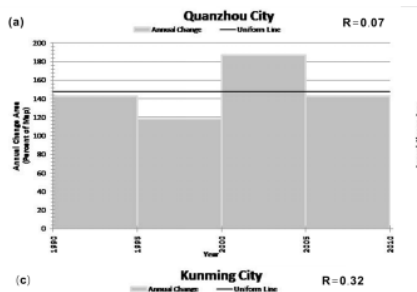

cities of central and western China are in the opposite direction to the cities of eastern China. It shows interesting patterns that some cities such as Changsha and Kunming are accelerating land change while Quanzhou is decelerating or regulating the speed of land change.
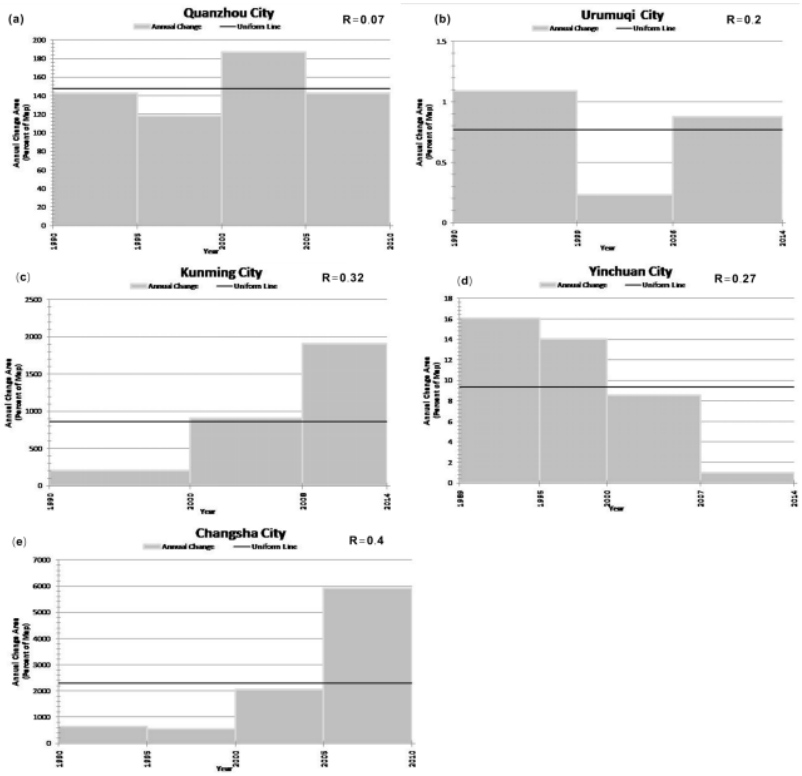

Figure 5. Land use instability: (a) The most stable cities, (b) The mid-ranked instability, (c) - (e) The most instability 
Figure 6 shows that regional comparison in typical urban change instability. If it is above the Uniform line, it belongs to unstable. And more far distance from the Uniform line of instability, more unstable land use change is. Quanzhou and Urumuqi's $\mathrm{R}$ value is below the Uniform line of instability, indicating that it is stable in land use change. And Quanzhou is more stable than Urumuqi. While Changsha City is the most the unstable among the five cities. In the five cities, the instability of urban land use change from small to large is as follows: Quanzhou, Urumuqi, Yinchuan, Kunming, Changsha City. The reason possibly is that the cities in the central and western China are experiencing earlier and middle urbanization stage while eastern city such as Quanzhou City has already entered into the later stage of urbanization.

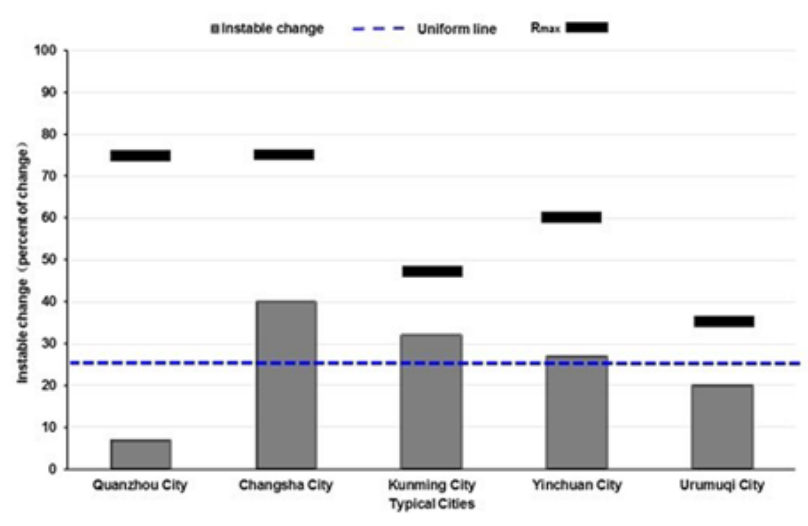

Figure. 6 Comparison of the land use change with instability in typical cities

\subsection{States maps in land use change}

Figure 7. is the categories transfer of 5 typical cities in land use change. Figure 7 (a) shows there are 5 land categories changed in Quanzhou among the six time intervals. The change happens mainly among 2 or 3 categories, i.e., Unused land $\rightarrow$ Built, Forest $\rightarrow$ Orchard $\rightarrow$ Built. And it occurs mainly in Dehua, Yongchun County and Jinjiang City. The changes between 2 categories and 3 categories are accounted for $75 \%$ and $23.4 \%$, respectively. In the Figure 7 (b), it occurs in around central lower-lying basin close to the Xiangjiang River riparian zone. Specifically, it mainly concentrated in the urban area of Changsha City and Wangcheng County where Cropland and Forest were converted to Built. From the Figure. 7 (c), we can see that There are 4 categories transition at most in Kunming but the change most is among the 3 categories. It is mainly located in the northern Dianchi Lake, i.e., Xishan, Wuhua and Guandu District. The change was adopted in this way: Forest $\rightarrow$ Crop land $\rightarrow$ Built, and Crop land $\rightarrow$ Orchard $\rightarrow$ Built, which is accounted for $64.8 \%$. The 2 categories changes are Water body $\rightarrow$ Built and Unused land $\rightarrow$ Built. In the northwest and south of Kunming, there are lots of Forests, which is gradually converted to the Built and Orchard due to the increased human activities. As for Yinchuan City in Figure.7 (d), the land transition happened mainly between 2 categories and 3 categories, which covers $85.9 \%$ and $13.6 \%$, respectively. It is mainly in this way: Cropland $\rightarrow$ Built, or unused $\rightarrow$ Cropland $\rightarrow$ Built, grassland $\rightarrow$ Unused land $\rightarrow$ grassland. At the end of the1990s, in the Helan Mountain Nature Reserve and western diluvial, there is much Unused land converted into grassland. The Figure. 7 (e) shows that the most conversion occurs between 2 categories, covering $95.4 \%$ of the total. Urumuqi City is located in western area and land use structure change experienced dramatically. A lot of Grassland and Cropland were converted to Built due to the economic development. 

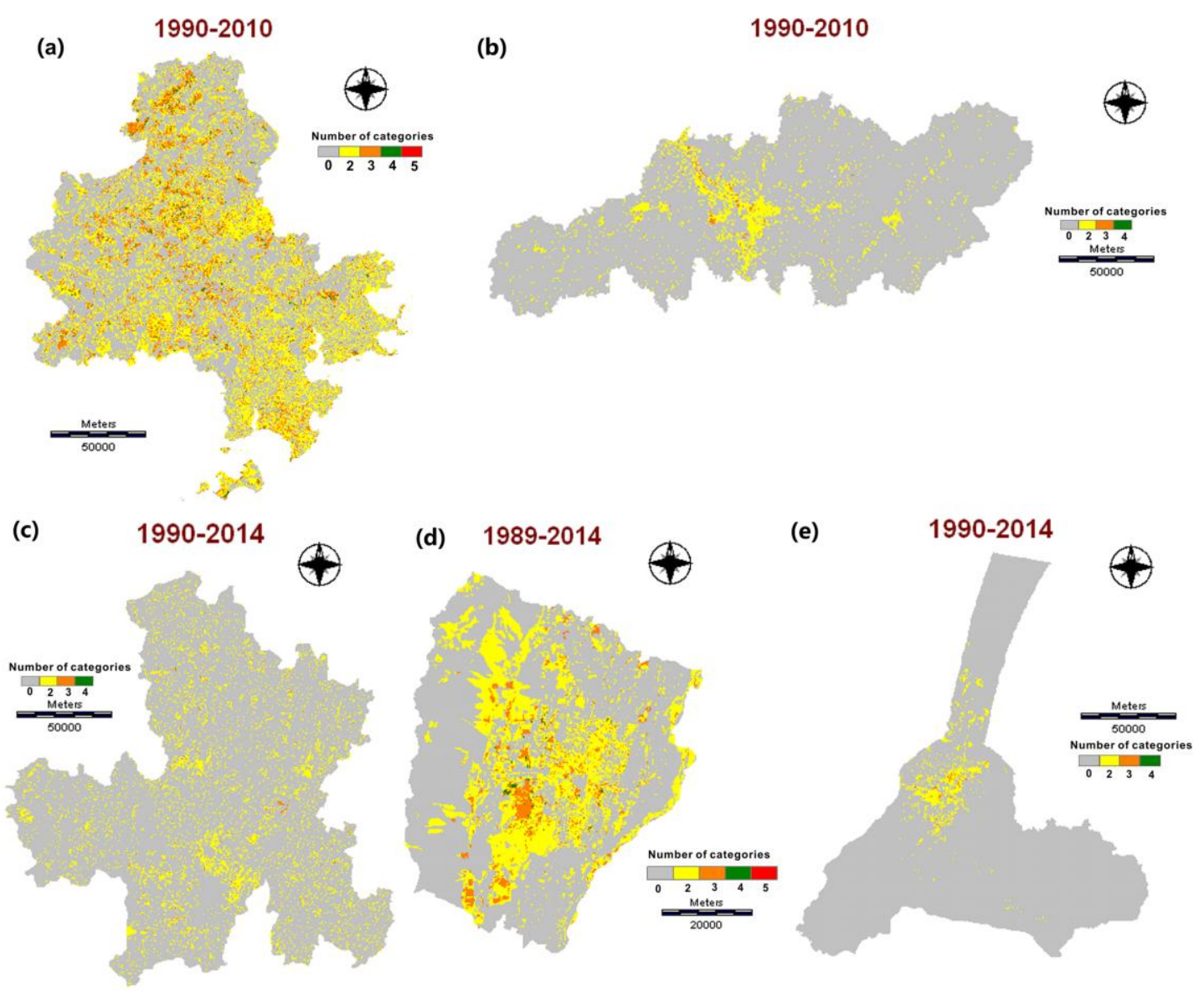

Figure. 7 The States map in the typical cities.

Figure. 8 compares the regional differences and commonalities of land use change states among the five typical cities. Quanzhou, Changsha, Yinchuan and Urumuqi mainly had the transfers between 2 categories, which accounts for their $75 \%, 96 \%, 85.9 \%$ and $95.4 \%$, respectively. Also, Kunming and Quanzhou Cities have a longer bar than the other cities in the " 3 to 5 categories transfers". But
Kunming changes mainly depends on shift which is the component of allocation difference(Pontius et al. 2014).The reason is that terrain and climate in Kunming have an impact on this transition. From the view of regional difference in China, except the Kunming the eastern region, i.e., Quanzhou City has more land categories involved changes than those cities in central and western region, i.e. Changsha, Yinchuan and Urumuqi City.

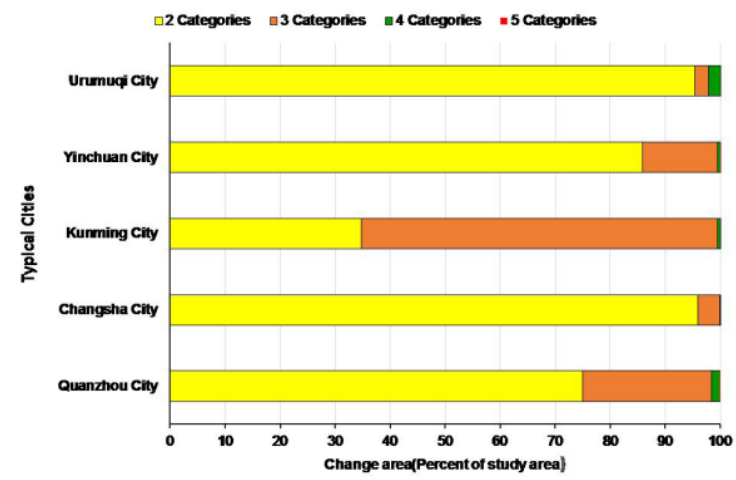

Figure. 8 The States changes in land use change 


\section{CONCLUSIONS}

This article used Flow Matrix, Incidents and States algorithms to analyze land use change instability in five node cities of China in the belt of Silk Road. On the whole, the more land transfer times and the more land categories involved changes occurs in Quanzhou City of eastern China than that in central and western China. Basically, the cities in central and western China such as Changsha, Kunming and Urumuqi City become instable while eastern city like Quanzhou City turns to be stable over time.

\section{ACKNOWLEDGEMENTS}

Key Project of Hunan Provincial Department of Education of China and the National Natural Science Foundation of China funded this work via grant 17A067 and grant 41271167. Also Recruitment Program of High-end Foreign Experts of the State Administration of Foreign Experts Affairs of China funded this work via grant GWD201543000243. The authors thank Robert Gilmore Pontius Jr, from Clark University, USA who gave us the programming on the Incidents algorithm and States algorithm.

\section{REFERENCES}

Aldwaik S., Pontius Jr R G., 2013. Map errors that could account for deviations from a uniform intensity of land change. International Journal of Geographical Information Science, 27(9), pp. 1717-1739.

Aldwaik S., Pontius Jr R G., 2012. Intensity Analysis to unify measurements of size and stationarity of land changes by interval, category, and transition. Landscape and Urban Planning, 106, pp. 103-114.

Aldwaik S., 2012. Fundamental concepts of intensity analysis to understand changes among categories. USA, Clark University, pp. 125-137.

Costanza R., R. d'Arge., 1997. The value of the world's ecosystem services and natural capital. Nature, 387(6630), pp. 253-260.
Chi W F., Shi W J., Kuang W H., 2015. Spatio-temporal characteristics of intra-urban land cover in the cities of China and USA from 1978 to 2010. Journal of Geographical Sciences, 25(1), pp. 3-18.

Chen J., Chang K., Karacsonyi D., et al, 2014. Comparing urban land expansion and its driving factors in Shenzhen and Dongguan, China. Habitat International, 43, pp. 61-71.

Chen Y M., Li X., Liu X P., 2014. Modeling urban land-use dynamics in a fast developing city using the modified logistic cellular automaton with a patch-based simulation strategy. International Journal of Geographical Information Science, 28(2), pp. 234-255.

Chneider A S., Mertes C M., Tatem A J., 2015. A new urban landscape in East-Southeast Asia, 2000-2010. Research Letters, 10, pp. 1-14.

Chen G L., Yang W M., Chi W F., 2013. Analysis of land use time-space Change characteristic in Kunming city. Anhui Agricultual Science Bulletin, 19(22), pp.10-13.

Chen Y L., Xin B G., LI X Q., 2015. The Preliminary Research on Relationship between the Change of Land Use and Urbanization in Changsha from 2003 to 2013. Economic Geography, 35(1), pp. 149-154.

Chen M., Liu W., Tao X., 2013. Evolution and assessment on China's urbanization 1960-2010: under-urbanization or over-urbanization? Habitat International, 38, pp. 25-33.

Duan Z Q., Zhang F R., Kong X B., 2005. Method for information mining of land use change and its application. Transactions of the CS AE, 21(12), pp. 60-66.

Enaruvbe G., Pontius Jr R G., 2015. Influence of classification errors on Intensity Analysis of land changes in southern Nigeria. International Journal of Remote Sensing, 31(1), pp. 244-261. 
Eastman J R., 2014. TerrSet Geospatial Monitoring and Modeling System. Worcester, MA: Clark University, pp. 345-389.

Gu C L., Wu L Y., Cook I., 2012. Progress in research on Chinese urbanization. Frontiers of Architectural Research, 1, pp. 101-149.

Holden E., 2004. Ecological footprints and sustainable urban form. Journal of Housing and the Built Environment, 19(1), pp. 91-109.

Huang J C., Chen S Q., 2015. Classification of China's urban agglomerations. Progress in Geography, 34(3), pp. 290-301.

Huang Z J., Wei D., He C F., 2015. Urban land expansion under economic transition in China: A multilevel modeling analysis. Habitat International, 47, pp. $69-82$.

Huang Y., Li F., Bai X., et al, 2012. Comparing vulnerability of coastal communities to land use change: analytical framework and a case study in China. Environmental Science \& Policy, 23, pp. 133-143.

Kuang W H., Chi W F., Shi J., 2014. The spatial and temporal differences of urban interior land cover structure in China and the United States metropolitan area. Acta Geographica Sinica, 69(7), pp. 883-895.

Gu C L., Pang H F., 2008. Study on spatial relations of Chinese urban system: Gravity model approach. Geographical Research, 27(1), pp. 1-12.

Lambin E F., Geist H J., Agbola S B., 2001. The cause of land-use and land-cover change: moving beyond the myths. Global Environmental Change, 11, pp. 261-269.

Lei S., 2014. Comparison of Land Use Changes between Case Areas from the Developed East and Less Developed Central China: A Case Study of the Changsha and Quanzhou City. Hunan: Hunan University of Science and Technology, pp. 23-30.

Liu J Y., Zhang Q., Hu Y F., 2012. Regional Differences of China's Urban Expansion from Late 20th to Early 21st Century Based on Remote Sensing Information. Chinese Geographical Science, 22 (1), pp. 1-14.

Liu R., Zhu D L., 2010. Methods for Detecting Land Use Changes Based on the Land Use Transition Matrix. Resources Science, 32(8), pp. 1544-1550.

Karacsonyi D., Chang K., 2014. Comparison of urban land expansion and population growth in the Taipei metropolitan region. Global Environmental Research, 18: (2), pp. 183-190.

Pontius Jr R G., Gao Y., Giner N M., 2013. Design and interpretation of Intensity Analysis illustrated by land change in Central Kalimantan, Indonesia. Land, 2(3), pp. 351-369.

Pontius Jr R G., Alí S., 2014. Quantity, Exchange, and Shift Components of Difference in a Square Contingency Table. International Journal of Remote Sensing, 35 (21), pp. 7543-54.

Qiao W F., Sheng Y H., Wan B., 2013. Land use change information mining in highly urbanized area based on transfer matrix: A case study of Suzhou, Jiangsu Province. GEOGRAPHICAL RESEARCH, 32(8), pp. 1497-1507.

Quan B., Bai Y., Romkens M J M., et al, 2015. Urban land expansion in Quanzhou City, China, 1995-2010. Habitat International, 48, pp.131-139.

Mertes C M., Schneider A., Sulla-Menashe D., 2015. Detecting change in urban areas at continental scales with MODIS data. Remote Sensing of Environment, 158, pp. 331- 347.

Runfola D M., Pontius Jr R G., 2013. Measuring the Temporal Instability of Land Change using the Flow Matrix. International Journal of Geographical Information Science, 27(9), pp. 1696-1716.

Seto K C., Fragkias M., Güneralp B., et al. 2011. A meta-analysis of global urban land Expansion. PLOS ONE, 6(8), pp. e23777. 
Schneider A., Mertes C M., 2014. Expansion and growth in Chinese cities, 1978-2010. Environmental Research Letters, 9, pp. 024008.

Liu J., Dietz T., et a, 2007. Complexity of coupled human and natural systems. Science, 317 (5844), pp. 1513-1516.

Wu J S., Liu H., Peng J., 2014. Hierarchical structure and spatial pattern of China's urban system: Evidence from DMSP/OLS nightlight data. Acta Geographica Sinca,69(6), pp. 759-770.

Xiao Z K., 2012. Urban Land Use and Land Cover Change and its Driving Factors: A case study of the Changsha-Zhuzhou-Xiangtan. Xiangtan: Hunan University of Science and Technology, 2012, pp. 45-51.

Yao Y L., 2014. Spatiotemporal Variation Characteristics and Causes of Land Surface Temperature in Typical City of Northwest Oasis. Gansu: Northwest Normal University, 2014, pp. 54-62.

Zara T., João C M., Pontius Jr R G., 2016. Evidence for deviations from uniform changes in a Portuguese Water bodyhed illustrated by CORINE maps: An Intensity Analysis approach. Ecological Indicators, 66, pp. 382-390.

Zhang Z X., Zhao X L., Wang X., 2012. Monitoring land use in China by remote sening. Beijing, China: Star Map Press, pp. 231-238.

Zhang Y J., Pontius R G., 2016. Method to summarize change among land categories across sequential time interval. Cartography and Geographic Information Science, In press.

Zhang Y J., 2011 Characterizing Land Changes over Several Points in time. USA. Clark University, pp. $16-22$. 